\title{
The Natural History of Diabetic Retinopathy
}

EVA M. KOHNER, MD, MRCP, The Royal Postgraduate Medical School, Hammersmith Hospital, London

Until recently the study of the natural history of diabetic retinopathy had to rely on description of lesions as observed through the ophthalmoscope. Although this method was adequate for recording the first appearance of new types of lesions or their complete disappearance, it was unreliable in indicating the severity of the lesions present. Furthermore, because all such descriptions were subjective, different observers may have given different interpretations.

The introduction of retinal photography, including fluorescence angiography, made possible the collection of permanent records of fundal appearances and, thus, the objective study of the natural history of diabetic retinopathy. Objective assessment of the severity of diabetic retinopathy became of the utmost importance when treatments such as pituitary ablation and photocoagulation became available. Both these treatments can save vision and both are potentially dangerous. Only careful comparison of the effects of treatment with the natural history of the various features of retinopathy will enable workers to decide which features to treat, and when to treat them.

This article describes the natural history of some of the lesions seen in diabetic retinopathy. The lesions described here were chosen partly because of their importance and partly because they illustrate methods for quantitative assessment of the natural history of different types of lesion. The work forms part of a prospective study on the natural history of diabetic retinopathy started at the Hammersmith Hospital in 1965.

MIGROANEURYSMS

Microaneurysms are the earliest ophthalmoscopically visible lesions in diabetic retinopathy. On ophthalmoscopy and colour photography only the larger ones, over about $20 \mu$ in diameter, are visible. Fluorescence angiograms show up many more, since even the smallest ones can be seen (Fig. 1). Microaneurysms are clearly-defined discrete lesions and therefore they can be counted on good quality fluorescence photographs. Hence, their natural history can be determined from fluorescence angiograms of the same retinal areas taken at different times. 


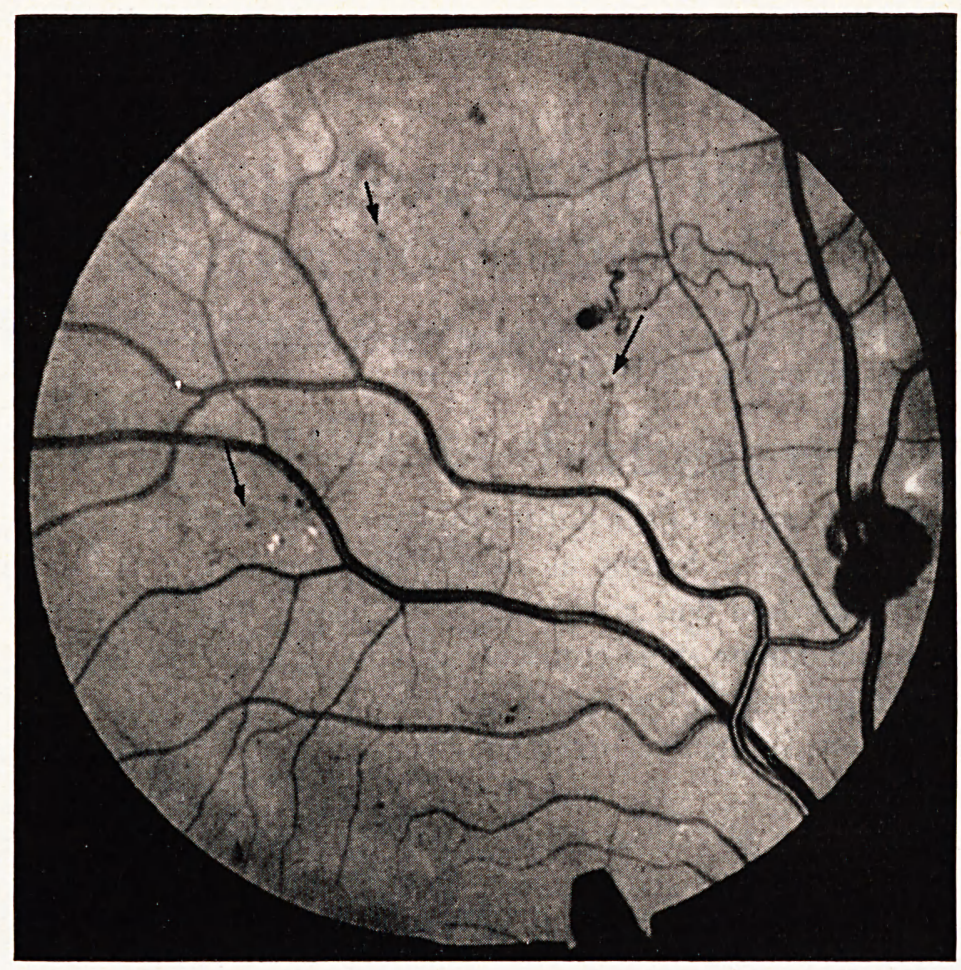

Fig. 1: (a) From a colour photograph of right superior temporal area of diabetic patient. Small dots indicate microaneurysms (arrows).

For the study, prints of known magnification are prepared. Microaneurysms present on the initial prints are indicated on diagrams, and appropriate symbols or colours are used on subsequent occasions to indicate whether microaneurysms remain unchanged, have disappeared or are a new feature. Thus, both the formation and the disappearance rate of microaneurysms $/ \mathrm{mm}^{2}$ retina can be calculated. The method is extremely time-consuming and therefore only a few patients can be studied. It was used to study the natural history of microaneurysms in 15 patients with a wide range of severity of diabetic retinopathy (Kohner and Dollery, 1970). The initial number of microaneurysms was variable and ranged from 18 to less than $1 / \mathrm{mm}^{2}$ retina. Almost all patients showed an initial steep decline in the number of microaneurysms surviving, and this rapid disappearance rate flattened out later. The mean initial disappearance rate was 10.5 per cent $/ \mathrm{month} / \mathrm{mm}^{2}$ retina and this slowed down to 0.9 per cent $/ \mathrm{month} / \mathrm{mm}^{2}$ retina in subsequent studies ranging from two to twenty-two months. In 8 of the 15 patients there was an actual increase in the number of microaneurysms surviving between two studies. It is possible but unlikely that this was due to variation in film quality, or that microaneurysms disappear and then reform at the same site. It is probable that the perfusion of microaneurysms is variable. 


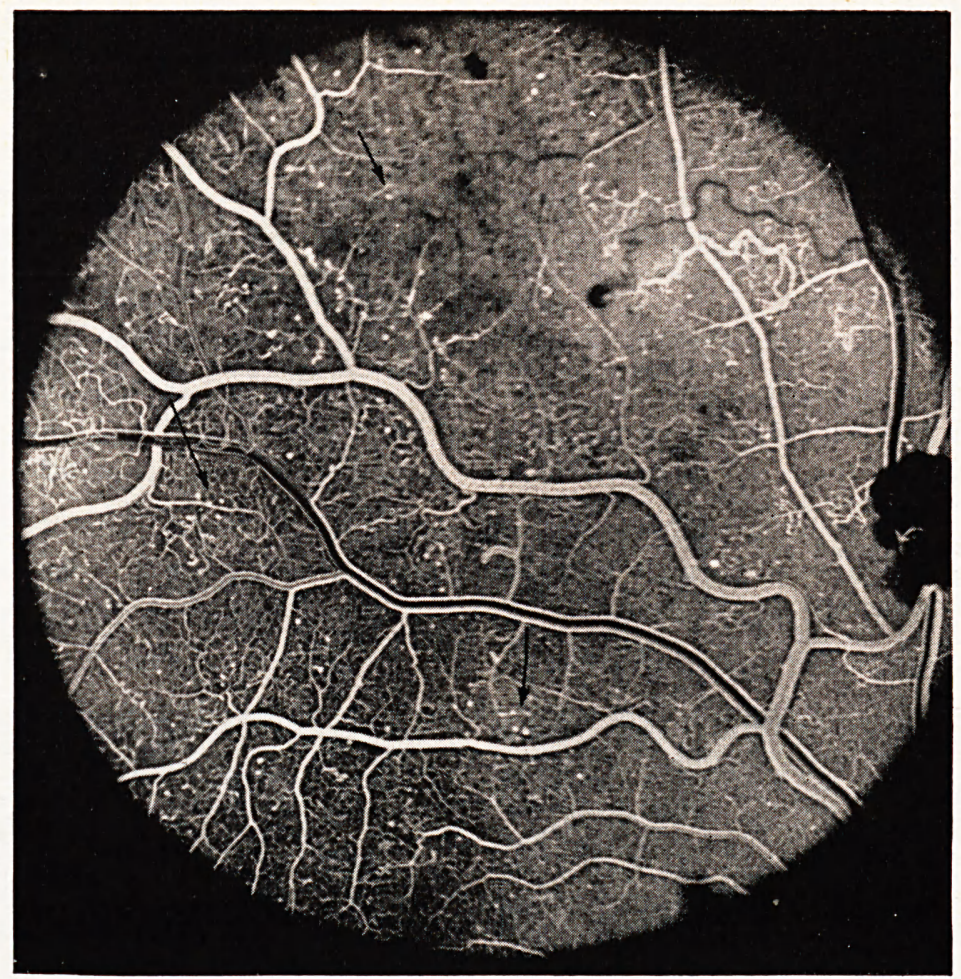

(b) Same as Fig. 1 (a) but fluorescence angiogram in capillary phase. Black dots indicate microaneurysms (arrows). More microaneurysms are seen than on colour photographs.

Some presumably became blocked from time to time by plugs of red cells and platelets. De Venecia and Davis (1967) found on digest examination of an enucleated eye that microaneurysms not perfused with fluorescein in life were indeed full of red blood cells.

The formation rate of new microaneurysms was variable. Patients presenting with visual symptoms formed more microaneurysms in the early and later studies than patients whose retinopathy was found on routine examination. The difference was not significant, probably because of the small numbers and because of the large standard deviation, but there was a definite trend $(p=0.07$ : Table 1). The formation rate of new microaneurysms rather than the disappearance of existing ones appears to determine the severity of the retinopathy, new microaneurysms indicating further progression of the microvascular lesions responsible for diabetic retinopathy.

COTTONWOOL SPOTS

Cottonwool spots as a feature of diabetic retinopathy were first recognised by Esmann et al. (1963) who found them in one-third of their patients. Of 136 patients with diabetic retinopathy studied at the Hammersmith Hospital between 1965 and 1968, 61 (43.8 per cent) had cottonwool spots. Of these 
J. Roy. Coll. Phycns Lond.

TABLE 1. Formation rate of microaneurysms

\begin{tabular}{|c|c|c|c|c|c|c|}
\hline & \multicolumn{2}{|c|}{ Overall Formation } & \multicolumn{2}{|c|}{ Early Formation } & \multicolumn{2}{|c|}{ Late Formation } \\
\hline & $\begin{array}{l}\text { Number } \\
\text { /Month }\end{array}$ & $\begin{array}{l}\text { Mean } \\
\text { Follow-up } \\
\text { (Months) }\end{array}$ & $\begin{array}{l}\text { Number } \\
\text { /Month }\end{array}$ & $\begin{array}{l}\text { Mean } \\
\text { Follow-up } \\
\text { (Months) }\end{array}$ & $\begin{array}{l}\text { Number } \\
\text { /Month }\end{array}$ & $\begin{array}{l}\text { Mean } \\
\text { Follow-up } \\
\text { (Months) }\end{array}$ \\
\hline $\begin{array}{l}\text { Patient with no visual } \\
\text { symptoms } \\
\text { (Mild retinopathy) }\end{array}$ & $0 \cdot 7 \pm 0 \cdot 6$ & $18 \cdot 3$ & $1 \cdot 0 \pm 0 \cdot 8$ & $3 \cdot 1$ & $0 \cdot 6 \pm 0 \cdot 5$ & $14 \cdot 2$ \\
\hline $\begin{array}{l}\text { Patients with visual } \\
\text { symptoms } \\
\text { (Severe retinopathy) }\end{array}$ & $1 \cdot 1 \pm 0 \cdot 7$ & $17 \cdot 3$ & $1 \cdot 2 \pm 0 \cdot 6$ & $4 \cdot 5$ & $1 \cdot 1 \pm 0 \cdot 7$ & $12 \cdot 8$ \\
\hline
\end{tabular}

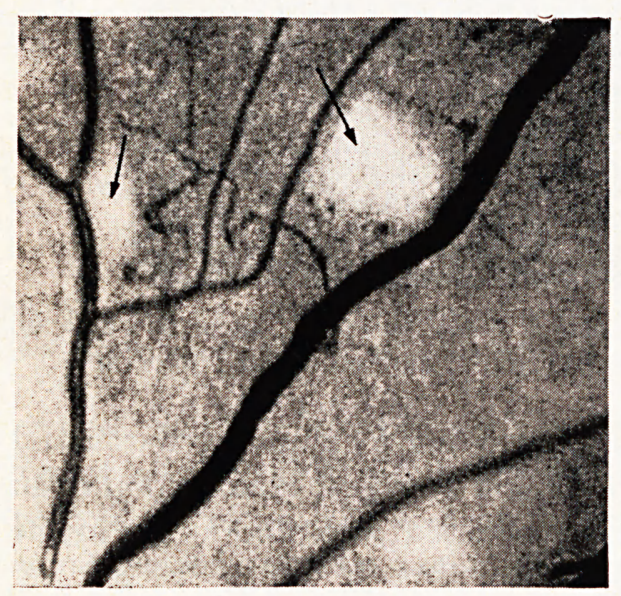

(a)

Fig. 2: (a) From a colour photograph of right superior area of a diabetic patient. Arrows point at cottonwool spots.

(b) Same as (a) but fluorescence angiogram in capillary phase. Areas of cottonwool spots are not perfused (arrows).

(c) Same as (b) but two seconds later. Arrows point at occluded arterioles.

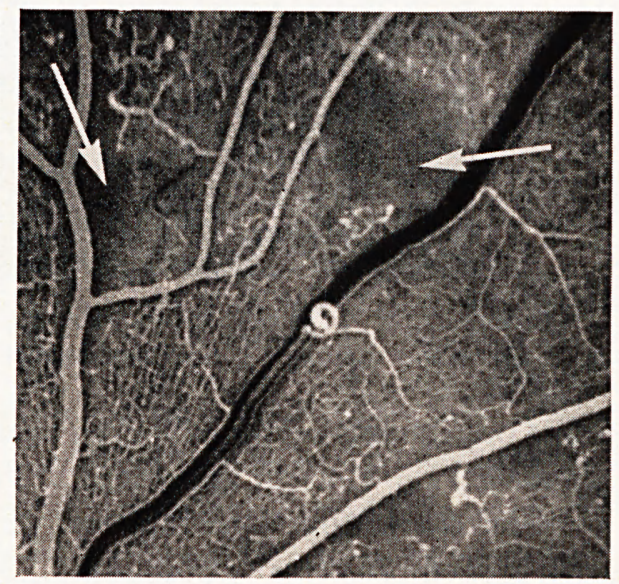

(b)

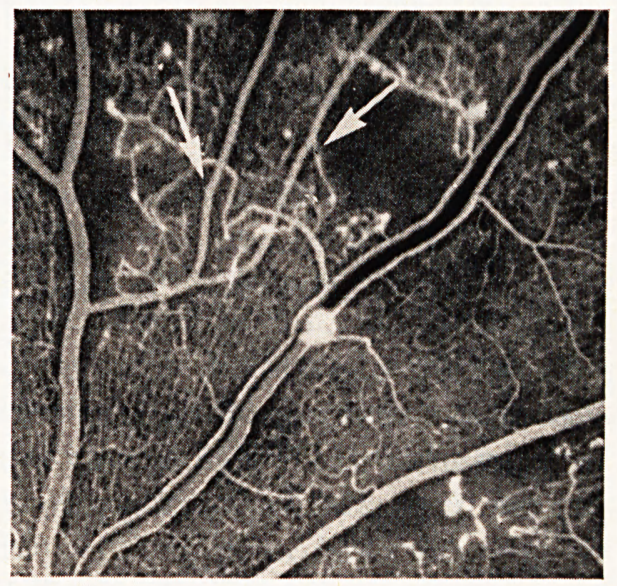


patients, 41 had consistently normal blood pressures and there were only five patients in whom the diastolic pressure exceeded $110 \mathrm{~mm} \mathrm{Hg}$ (Kohner et al., 1969). Cottonwool spots are therefore a feature of the retinopathy itself and not of associated hypertension.

The area covered by the cottonwool spot can be measured from retinal photographs using a planimeter. Since most are within three disc diameters from the disc margin, all the cottonwool spots present can be included in a quantitative study.

Although small areas of capillary non-perfusion are probably the earliest manifestation of diabetic retinopathy, even preceding microaneurysms, cottonwool spots represent areas of capillary non-perfusing with the addition of arterial or arteriolar occlusion (Fig. 2). Both in hypertensive and diabetic retinopathy, cottonwool spots represent retinal infarcts, the result of arterial occlusion.

However, the natural history of cottonwool spots is very different in diabetic and treated hypertensive patients. Hodge and Dollery (1964) have shown that after introduction of effective hypotensive therapy cottonwool spots rapidly disappear, their half-life (the time interval during which the area covered by cottonwool spots present at the initial study is reduced by 50 per cent) being six weeks. In diabetics, cottonwool spots persist much longer. In only 2 of 5 diabetics under the age of forty years did cottonwool spots disappear during a period of up to twenty months, and their half-life was eleven months. This slow disappearance became even more striking in patients over the age of forty years (Fig. 3), and the mean half-life of the cottonwool spots increased

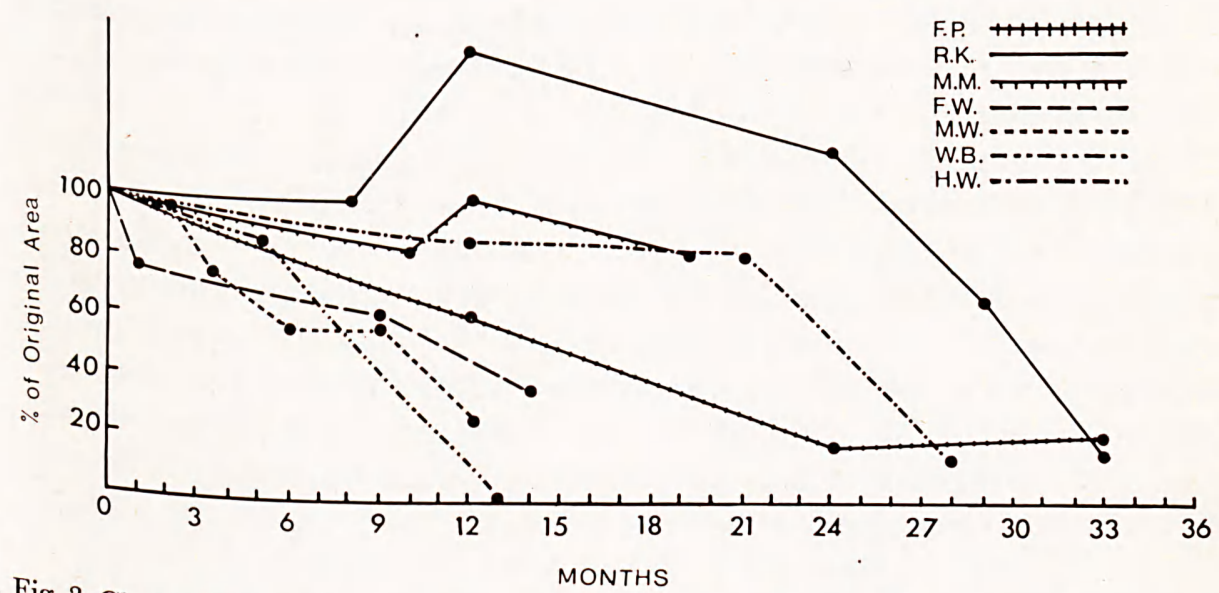

Fig. 3. Change in area of cottonwool spots in patients over the age of forty years. Area covered on first study is indicated as $100 \%$ (from Kohner et al., 1969). 


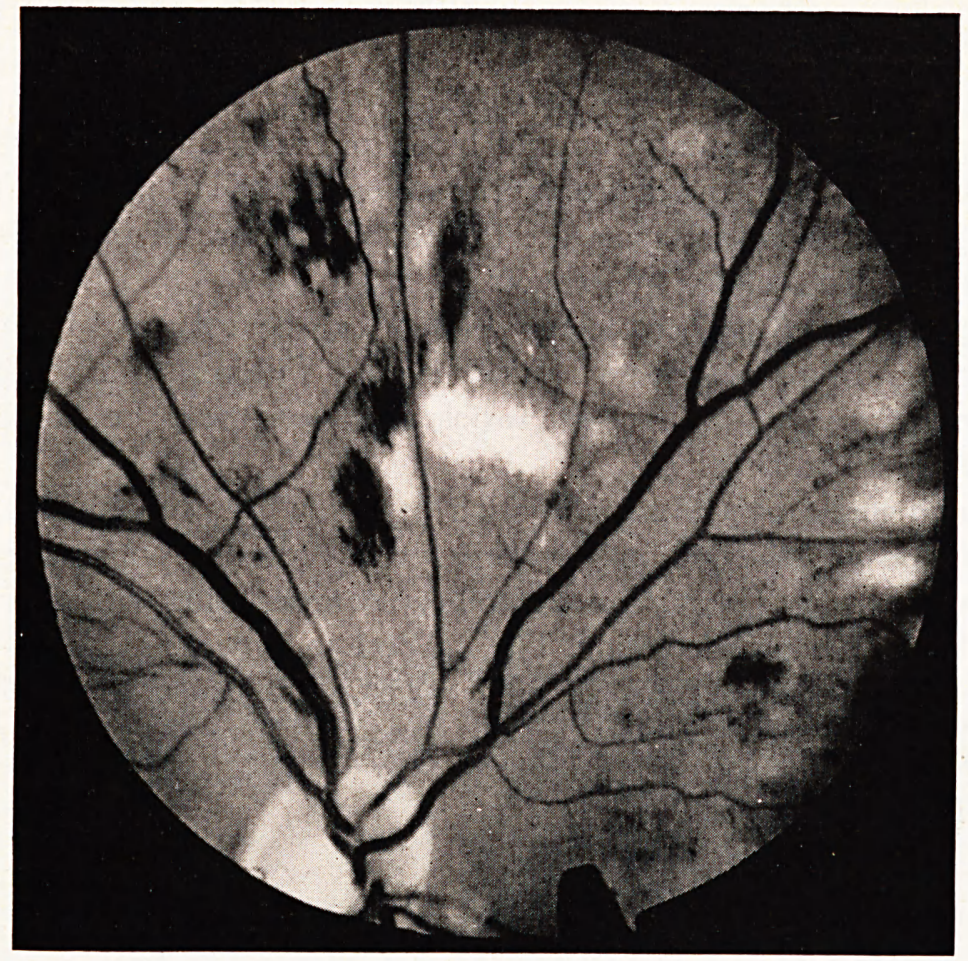

Fig. 4: (a) From a colour photograph of right superior area of normotensive diabetic patient with more than 10 cottonwool spots in this eye.

to $17 \cdot 2$ months. The prolonged presence of cottonwool spots may be related to the widespread capillary abnormalities in diabetic patients preventing removal of cellular debris following infarction of the retina.

Even when cottonwool spots disappear, re-perfusion of the area does not occur. In only three patients could revascularisation of part of the area of capillary closure be observed as long as one year after disappearance of cottonwool spots.

The most important fact about cottonwool spots in diabetic retinopathy is their prognostic significance. While up to five cottonwool spots are seen commonly, the presence of many, say eight in any one eye, in the absence of hypertension indicates that the retinopathy has entered a more rapidly advancing stage. It is these patients who are likely to develop proliferative retinopathy within the next 6 to 18 months (Fig. 4). Therefore, they should be evaluated carefully at frequent intervals, especially if treatment is contemplated. Treatment, if it is to be successful, must be applied before the development of irreversible retinitis proliferans.

Of all the features of diabetic retinopathy, formation of new vessels is the most 


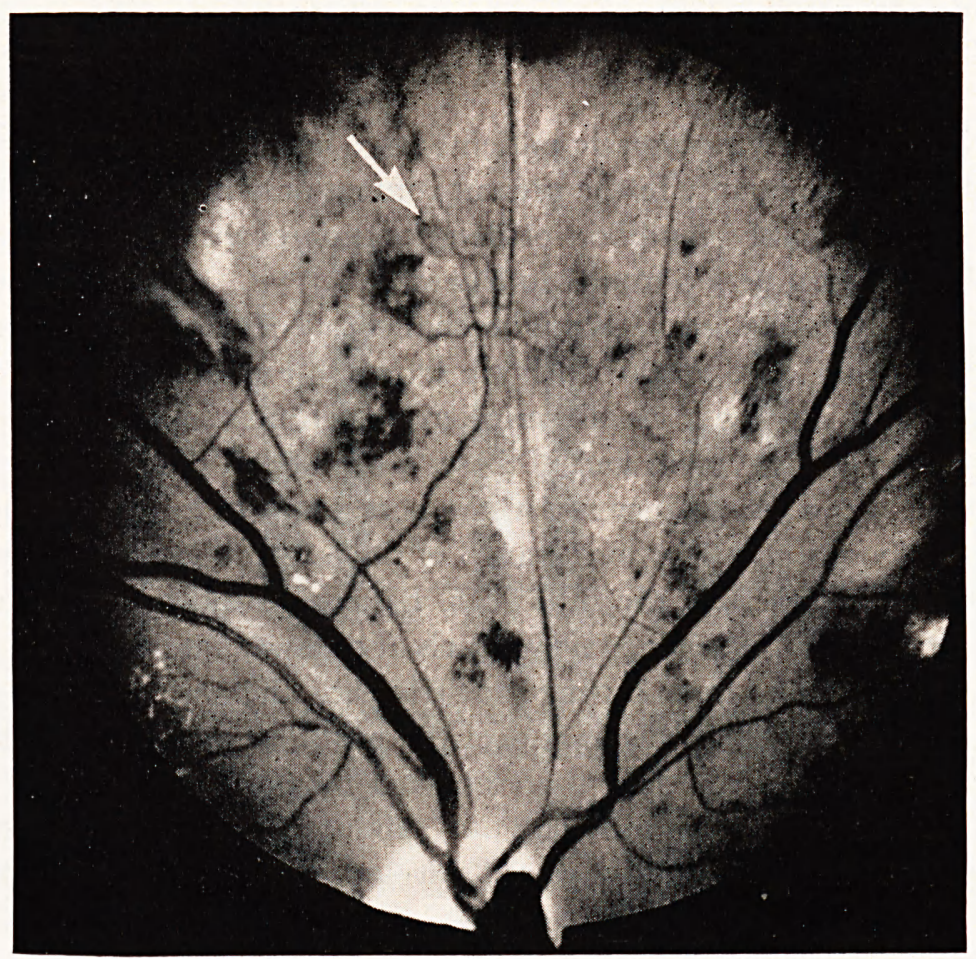

(b) Same as (a) but one year later. Still many cottonwool spots present. New vessels have now developed (arrow).

important, because their progression and complications frequently lead to blindness. The assessment of new vessels is more difficult than that of microaneurysms and cottonwool spots. We have used a grading system to study their severity. The system is a photographic one based on four standard photographs of each retinopathic feature, chosen arbitrarily but indicating clear-cut differences in the severity of the feature studied. This allows for six grades of severity from 0 to 5 . When studying the natural history of new vessels even this relatively simple system can be difficult to use, or become misleading, since new vessels may become unassessable because of vitreous haemorrhage obscuring the view or retinitis proliferans replacing the new vessels. One therefore has to do an even more simple analysis indicating whether new vessels improve, progress, or remain unchanged.

In the natural history of new vessels, two groups of patients were studied. Fifty-one patients, referred for consideration of pituitary ablation for symptomatic diabetic retinopathy, are labelled as 'severe retinopathy' in the following paragraphs. There were 90 patients without visual symptoms who were found to have retinopathy on a diabetic clinic survey. This retinopathy is called 'mild' in this paper. (It must be emphasised that the severity of individual lesions was not necessarily related to the presence or absence of visual symp- 
toms. Nor did all asymptomatic patients have normal or even near normal vision. 'Mild' retinopathy in the present context only means that the patient did not spontaneously complain of deterioration of vision.) These patients were followed for a period from 1 to 5 years.

Chances of developing new vessels. The chances of developing new vessels in an eye which has none to start with are shown in Fig. 5.

In the 51 patients with visual symptoms, when first seen there were only 24 eyes without new vessels and of these, 5 developed them within the first year. There was a steady increase in the percentage of eyes developing new vessels. Of those studied for five years 3 of the 6 free of lesions for four years developed new vessels in the fifth year. Patients without visual symptoms ('mild' retinopathy) developed new vessels at a slower rate. Only 15 per cent of 140 eyes developed them during the first year. This rose to 20-25 per cent (Fig. 5) and remained at this level over the next four years. Even this figure of 20 per cent is higher than that reported by Burditt et al. (1968) from Oxford. These workers found that only about 18 per cent of those with haemorrhages and/or exudates would develop new vessels over a period of

$\begin{array}{llcccc}\text { NUMBER OF } & 24 & 19 & 8 & 11 & 6 \\ \text { EYES WITHOUT } & 140 & 111 & 82 & 78 & 68 \\ \text { N.V. AT START } & & & & & \end{array}$

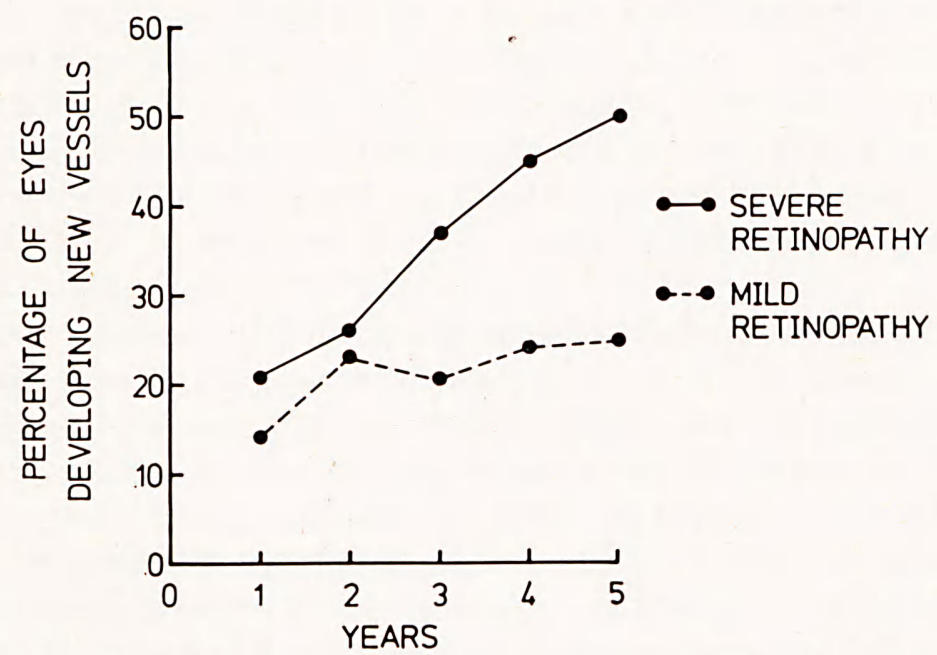

Fig. 5. Graph illustrating the percentage of eyes that develop new vessels each year if they had none to start with. NV $=$ New vessels. Severe retinopathy $=$ those with visual symptoms when first seen. Mild retinopathy $=$ those whose retinopathy was discovered on a diabetic clinic survey. 


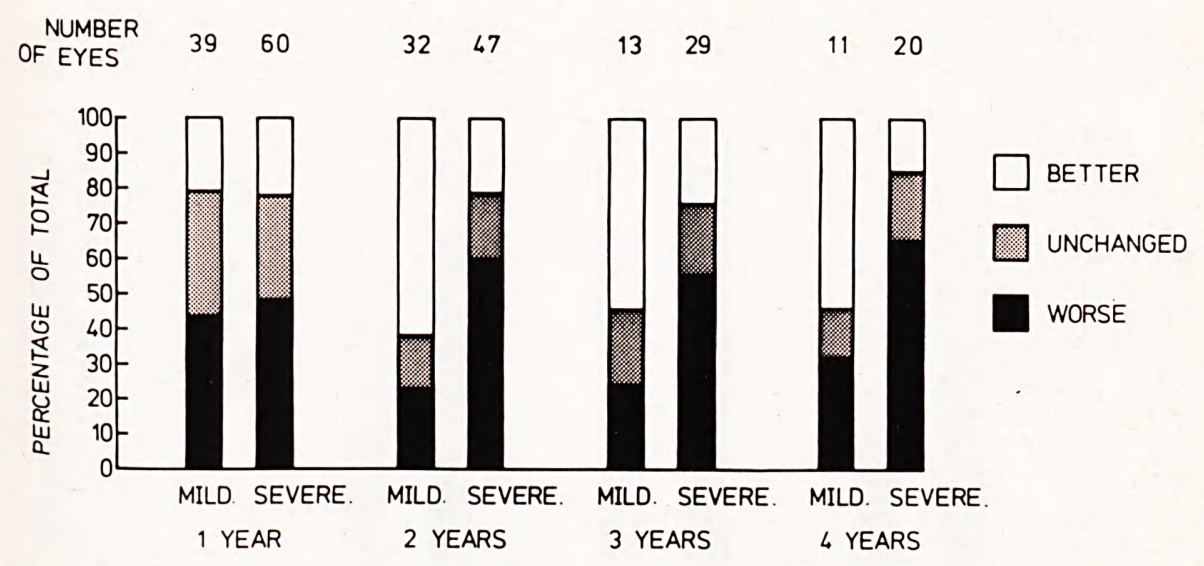

Fig. 6. Histograms indicating the percentage of eyes with new vessels improving, remaining unchanged or deteriorating over four years in patients with visual symptoms ('severe') and those without visual symptoms ('mild').

ten years. More accurate diagnosis with yearly examination and objective records in this study are probably responsible for differing results.

Progression of new vessels. The mean grading of new vessels once present changed little over the years. This could be due to the fact that on photographic grading, as on direct ophthalmoscopy, new vessels cannot always be differentiated from dilated capillaries, the latter being more frequently reversible. In addition, the number of eyes becoming unassessable increased over the years and thus only those with milder lesions could still be graded.

Figure 6 shows the percentage of eyes that improved (by 1 grade or more), remained unchanged $( \pm 0.9$ grade) or deteriorated (by 1 grade or more or became unassessable for over six months with deterioration of vision due to the new vessels). During the first year there was no difference between those with and those without visual symptoms ('severe' or 'mild' retinopathy). Thereafter, there were significantly more deteriorating and fewer improving in the 'severe' retinopathy group compared with the 'mild' retinopathy group. Although the initial gradings of those with visual symptoms was higher at first, this alone could not account for the difference in the results.

Subdividing the patients according to the site of the new vessel formation gave the full answer. In Fig. 7 the eyes were subdivided into those that had new vessels in the retinal periphery only, and those in which they arose from the optic disc only or the optic disc and the retinal periphery. Using the chi square test the number of those improving was always significantly smaller in those with new vessels arising from the disc. At two and three years those with disc vessels had a significantly greater number deteriorating. After three 
J. Roy. Coll. Phycns Lond.

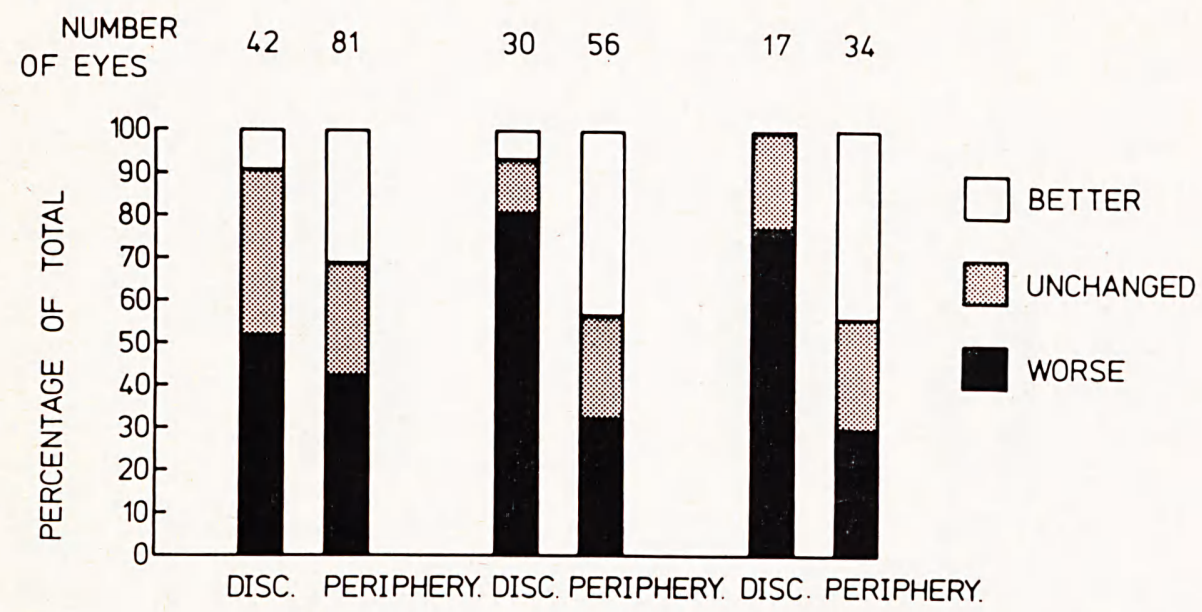
1 YEAR
2 YEARS
3 YEARS

Fig. 7. Chances of eyes improving, remaining unchanged or deteriorating in eyes with new vessels arising from the optic disc compared with eyes in which new vessels arise from the retinal periphery only.

years too few with disc vessels could still be followed for valid analysis.

It appears, therefore, that the worse prognosis for new vessels in patients with visual symptoms is due to more of them having new vessels on the disc than those without visual symptoms.

\section{VISUAL AGUITY}

As far as the patients are concerned, the only important factor in diabetic retinopathy is the visual acuity, which can be measured with relative accuracy and gives a numerical answer that is easy to quantitate. We have therefore studied the progression of the visual acuity in those with and those without visual symptoms when first seen.

Of those with visual symptoms, just under 60 per cent had good vision to start with and 40 per cent maintained this over five years. Nearly 20 per cent of the eyes were blind at the first assessment and this increased to nearly 50 per cent. There was much less change in the percentage of those with initially poor vision (Fig. 8). The only comparable figures are those of Caird and his co-workers (1968) who found that within one year of the first vitreous haemorrhage approximately one-third of those with initially good vision maintained it, one-third became blind, and one-third deteriorated to poor vision. At three years the figures were similar. Not all patients in this group had a vitreous haemorrhage and this probably accounts for the fact that two-thirds of those with initially good vision were able to maintain this over five years. 


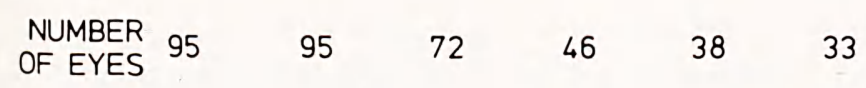

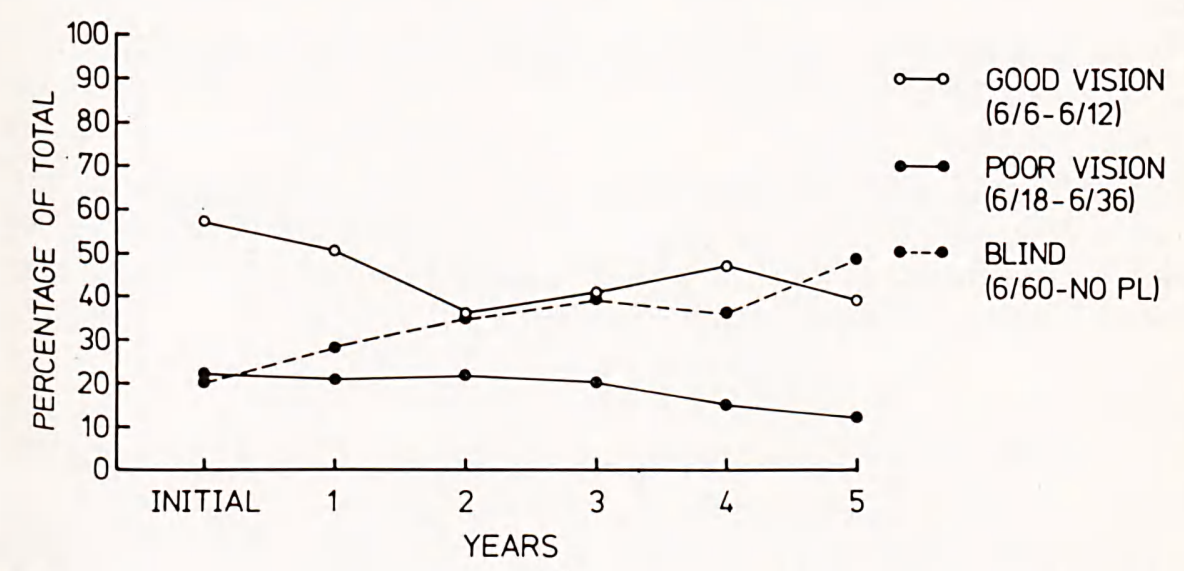

Fig. 8. Graph showing percentage eyes with good, poor, and no vision over a period of five years in patients with visual symptoms when first seen.

Patients without visual symptoms when first seen had a good five-year prognosis. Eighty per cent of the eyes studied retained good vision and the number of eyes with poor vision and blindness changed only a little in five years (Fig. 9).

$\begin{array}{lllllll}\text { NUMBER } & 161 & 161 & 145 & 125 & 104 & 79 \\ \text { OF EYES } & & & & & \end{array}$

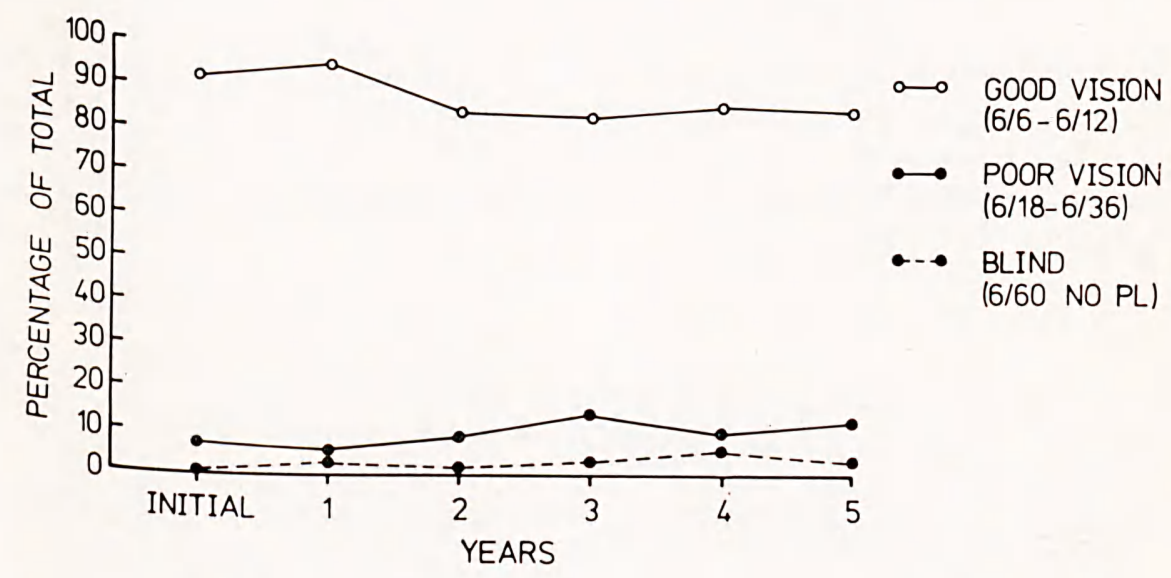

Fig. 9. Same as Fig. 8, but for patients with no visual symptoms. 
The causes of visual loss (visual acuity between $6 / 18$ and no perception of light) were different in those with and those without visual symptoms when first seen. Of the 161 eyes studied in the patients without visual symptoms 29 lost vision. Cataract accounted for 11 of these and new vessels and their complications for only 7 . Of 95 eyes with visual symptoms, 63 developed visual impairment over the five years. In 47 eyes this was due to the new vessels and their complications. This figure again emphasises the importance of new vessels in the prognosis of diabetic retinopathy. It is because of this poor visual prognosis that diabetic retinopathy should be treated before irreversible fibrous retinitis proliferans develops.

\section{GONGLUSIONS}

The quantitative evaluation of the natural history of diabetic retinopathy became possible with the introduction of retinal photography.

Prospective studies of the natural history of diabetic retinopathy indicate that the rate of formation of new microvascular lesions such as microaneurysms and cottonwool spots are more important than their disappearance. In particular, the appearance of many cottonwool spots in any eye in the absence of hypertension is of prognostic significance, heralding the early onset of proliferative lesions.

New vessels develop yearly in 20 per cent of the eyes not so affected within two to five years of the initial study in patients without visual symptoms. In those with visual symptoms up to 50 per cent will form new vessels five years after the first visit. The five-year prognosis for vision in patients without visual symptoms at the first study is good unless they develop new vessels arising from the optic disc.

\section{Acknowledgements}

This work was supported by the Wellcome Trust.

This article is based on a paper read at the Medical Ophthalmology Conference held at the Royal College of Physicians in June 1971.

\section{References}

Burditt, A. F., Caird, F. I. and Draper, F. J. (1968) Quarterly Fournal of Medicine, 37, 303.

Caird, F. I., Burditt, A. F., and Draper, F.J. (1968) Diabetes, 17, 121.

Esmann, V., Lundbaek, K. and Madsen, P. H. (1963) Acta medica Scandinavica, 174, 375.

Hodge, J. V. and Dollery, C. T. (1964) Quarterly Journal of Medicine, 33, 117.

Kohner, E. M. and Dollery, C. T. (1970) European Fournal of Clinical Investigation, 1, 136.

Kohner, E. M., Dollery, C. T. and Bulpitt, C. J. (1969) Diabetes, 18, 691.

De Venecia, G. and Davis, M. D. (1967) Investigative Ophthalmology, 6, 555. 